\title{
English Language Component of the Mature Students' Entrance Examinations into Ghanaian Universities: Placement, Diagnostic or Both?
}

\author{
Ramos Asafo-Adjei \\ Centre for Languages and Liberal Studies, \\ Communication and Media Studies Section, \\ Takoradi Technical University, Takoradi, Ghana \\ Ernest Kwesi Klu \\ Department of English, University of Venda, \\ Venda, South Africa \\ Albert Agbesi Wornyo \\ Department of Communication and Media Studies, \\ University of Education, Winneba, Ghana
}

DOI: https://doi.org/10.36941/ajis-2021-0110

\section{Abstract}

One way that Ghanaian universities admit undergraduate students is an examination organised for candidates who are twenty-five years and above. This examination is known as the Mature Students' Entrance Examinations (MSEE). This paper argues that the English language component of the MSEE should not only be used for placement purposes, but, also, for diagnostic purposes. A desk survey approach to research was adopted involving 43 relevant literature which were reviewed and synthesised. The study indicates that academic writing, referred to as Communication Skills, falls under the domain of English for Academic Purposes in an English as a Second Language setting like Ghana. It is further advanced that Communication Skills is essential for the performance of students in school. The paper, therefore, argues for the English language component of the MSEE to be used not only for placement purposes but for diagnostic purposes. The study recommends that the latter approach should be included since it will help improve the performances of students in Communication Skills.

Keywords: Communication Skills, diagnostic, English for Academic Purposes, MSEE, placement

\section{Introduction}

Examinations are an essential component of the activities of teaching and learning, and all teachers and learners must participate in examination activities (Xiaojiang, 1991). Similarly, Boud (1995) indicates that examinations are integral components of the educational process. They are very key in assessing the impact of lessons and also in the measurement of the knowledge levels of candidates. 
Carroll (1980) defines examinations as procedures designed to elicit certain behaviours from which one can make inferences about certain characteristics of an individual. Similarly, Brown (2004) describes examinations as formalised sets of techniques for measuring a person's ability or knowledge. On their part, Hanna and Dettmer (2004) define examinations as the ways instructors gather data about their teaching and their students' learning. On the goal of examinations, Brown (2004) posits that examinations have the 'goal of placing test takers on a continuum across a range of scores and to differentiate test takers by their relative ranking' (p. 67).

According to the literature, there are four types of examinations. Berry (2018), for instance, identifies proficiency, placement, diagnostic and achievement as the four types of examinations. In Berry's view, proficiency examination is meant to measure test takers' abilities, mostly within a particular domain (academic, business, medical). Placement examination provide assessors with information based on which test takers can be placed on ideal/acceptable levels of language programmes; such placements are based on specific scores obtained by test takers in such placement tests.

Diagnostic examination is meant to identify areas that test takers exhibit weaknesses so that appropriate support can be given them to help them to improve. Put differently, diagnostic examinations are used by language assessors to make diagnostic inferences about learners' strengths and weaknesses and to utilise the outcomes of such examinations for positive changes in their learning (Reed, 2006; Jang \& Wagner, 2013). Harding, Alderson and Brunfaut (2015) and Lee (2015) have decided the general features of diagnostic language assessment. One of the key defining principles within the framework of diagnostic assessment is that it should relate to some future treatment. The general purpose of using a test for diagnostic purpose is that it is intended to guide teaching and learning in the future. Berry (2018) further advances that achievement examination is 'intended to reflect achievement or progress over a course of study and can be either formative, during a course of study, or summative, at the end of the course' (p. 3). Specifically, on formative and summative examinations, Hanna and Dettmer (2004) opine that formative examination is used by assessors to provide feedback and information as learning goes on. Summative examination, on the other hand, takes place after the learning has been completed, and it provides information and feedback that sum up the teaching and learning process.

Placement examination offers test takers the opportunity to be selected usually for admission purposes (Burdman, 2012). One use of placement examination is that it is the means through which candidates get the chance to study at the university level. For instance, Zwick (2002) indicates that in North America, there are numerous standard placement examinations. For college entrance, educators use, for instance, the Scholastic Assessment Test (SAT). For admission to graduate and professional school, educators use the Graduate Record Examinations (GRE), the Medical College Admission Test (MCAT), the Law School Admission Test (LAWST) and the Graduate Management Admission Test (GMAT) (Fletcher, 2009).

In West Africa, placement examinations are equally used by universities to select potential candidates for enrolment into various undergraduate and post graduate courses of study. In Ghana, one popular route through which individuals who are desirous of gaining admission into universities to study undergraduate programmes use is an examination organised internally by the universities to select candidates for placement. This examination is known as 'Mature Students' Entrance Examinations". Candidates are deemed qualified to write this examination on condition that they are not less than twenty-five years of age. Candidates must, in addition, have prior working experience (recognition of prior learning) in the fields that they seek to study. The common practice is that candidates are examined in three areas - English language, Mathematics and a subject specific paper. Candidates are expected to pass all the papers before they are considered for placement.

This paper argues that the English language component of the MSEE could be used not only for placement purposes but also for diagnostic purposes to identify those candidates who need extra academic support so that they can be given the needed support. That is, the placement purpose alone that the examination is currently used for is inadequate since it is not an end in itself but a means to 
an end. That end is for the candidates to function effectively within the academic discourse community through standard performances (exhibition of the required language skills) in the Communication Skills course that they offer mostly in the first year in the universities. As Baldauf and Dawson (1980) advance, students need the required academic language skills to enable them communicate effectively within the academic discourse community. The present situation where the MSEE is used for only placement purposes puts students who need extra academic support in certain language skills at the risk of not getting the needed support. Kim (2011) indicates that there has been much interest in the use of diagnostic assessment information to inform instructional activities, but there have been few attempts to link a diagnostic approach to the teaching of English for Academic Purposes (EAP).

In order to achieve this, the paper emphasises that language skills are needed by students to succeed in the university and discusses the importance of diagnostic assessment. The nature of the EAP course in Ghanaian universities is presented. The use of the English language component of the MSEE for only placement purposes and its effects on students' performances is explained after which the paper argues for the inclusion of the diagnostic/intervention approach to help enhance the teaching of the Communication Skills course to improve the performances of students.

\section{The Use of Assessments for Diagnostic Purposes}

Briggs, Alonzo, Schwab and Wilson (2006) opine that teachers use diagnostic examination to understand students and guide instruction. El-Hamid (2011) adds that diagnostic examination identifies students who lack prerequisite knowledge, understanding or skills. In the view of De Pierola (2014), diagnostic examination refers to the gathering and systematic evaluation of detailed data using students' knowledge and skills in a specific learning area. De Pierola adds that such data may be gleaned from assessments that focus on key knowledge and concepts. Berry (2018) espouses that diagnostic examination is meant to identify areas that test takers exhibit weaknesses so that appropriate support can be given them to help them to improve. Put differently, diagnostic examinations are used by language assessors to make diagnostic inferences about learners' strengths and weaknesses and to utilise the outcomes of such examinations for positive changes in their learning (Jang \& Wagner, 2013). A typical example of an examination that can be put to such use is the English language component of the MSEE since it specifically tests students' English language knowledge and skills based on which they are granted or denied admission into Ghanaian universities.

Diagnostic assessment is especially used by language teachers to determine learners' strengths and weaknesses earlier in a language programme so that content is designed to select tasks and activities in a manner that will accommodate students (Reed, 2006). Diagnostic assessment is not only conducted to know the strength and weaknesses of learners, but also, it is used in testing learners and offering instructional interventions (Sternberg \& Grigorenko, 2002). Diagnostic assessment goes hand in hand with providing learners with feedback on their performances, and this helps for the appropriate instructional activities and tasks to be designed to meet the needs of learners. Jang and Wagner (2013) postulate that diagnostic feedback is crucial because it provides learners with information that positions them to reflect on their learning so as to undertake necessary remedial action(s) to improve upon their learning as and when necessary. As Alderson (2005) avers, 'test results and feedback should be provided as soon as possible after the test...the content of diagnostic tests may be based on material which has been covered in instruction or which will be covered shortly. Alternatively, it may be based on a detailed theory of language proficiency ( $p$. 256-257)'.

According to literature, there are many advantages associated with the application of diagnostic examination. El-Hamid (2011), for instance, suggests that diagnostic examination provides information essential to teachers in designing appropriate programmes for students. Consistent with El-Hamid's position, De Pierola (2014) avers that diagnostic examination helps teachers/assessors to 
identify students' current knowledge, to clarify misconceptions before teaching takes place and to know students' strengths and weaknesses so that lessons can be better planned. It, additionally, helps to determine the IQ level of an entire class to check the students' ability to handle particular tasks given them. Essentially, diagnostic examination aims to reveal specific knowledge and skill information about learners so that gaps found to exist in students' knowledge and skills can be duly addressed through the design and implementation of appropriate pedagogical interventions.

Tozcu (2015), however, notes that despite the advantages of diagnostic assessment, many practitioners disregard it. In a study conducted by Sandra and Scaife (2012), it was found that diagnostic assessment was neglected by lecturers. The study reported a failure on the part of the lecturers to apply diagnostic assessment in their instruction. In many language teaching courses, instructors just use the existing textbooks that have been designed for the courses and carry on with the activities and tasks in the textbooks without taking into consideration the strengths and weaknesses of the learners. This practice is not good enough. What happens is that the instructors follow the instructional activities from the beginning of the programme without knowing fully the abilities of the learners.

Using tests taken by learners for diagnostic purposes, therefore, provides a link between testing and instruction. The diagnostic test is used to inform how content should be selected and ordered to facilitate teaching and learning. Diagnostic teaching makes assessment and instruction continuous processes where assessment informs the teacher about the efficacy of previous instruction and how to organise new instruction to build on the knowledge of the learners (UNESCO, 2005).

\section{Methodology}

This paper argues that the English language component of the MSEE into Ghanaian universities should not only be used for placement purposes, but, also, for diagnostic purposes. Hence, a qualitative desk survey approach to research was adopted. Secondary data relevant to the study were obtained from books, journals, reports, the internet and a thesis. Some existing literature on placement examinations, diagnostic examinations, English for academic purposes and its related issues were reviewed and synthesised accordingly. The study covered 43 relevant literature; out of the 43 literature, 22 were journal articles, 16 were books, 3 were working papers and 2 were reports. Literature was accessed via Google search engine and google scholar.

\section{Findings and discussion}

This domain of this article highlights the nature of English for Academic Purposes (EAP) as used in Ghanaian universities and the use of the English language component of the MSEE for placement purposes and its effects on students.

\subsection{The nature of English for Academic Purposes in Ghanaian universities}

Baldauf and Dawson (1980), Afful (2007) and Kudom-Gyasi, Nartey and Coker (2011) are among the researchers who have established that the English language plays a central role in the overall performances of students in various fields of study in universities. Wornyo and Klu (2018) espouse that the English language skills that university students are taught to enable them function effectively in the academic discourse community falls under the domain of English for Academic Purposes (EAP). Within the Ghanaian context, EAP course is commonly referred to as 'Communication Skills'; other nomenclatures such as: 'Academic Writing' and 'Language and Writing Skills' are used.

Communication Skills is a mandatory course that the first years in both public and private universities take for both the first and second semesters to give them the necessary foundation for higher learning tasks, and it has a weight of two or three credit hours, depending on the university offering it. Generally, the first semester syllabi for the various universities/tertiary institutions are 
organised around topics such as: notes, reading, spelling, punctuation marks, words, phrases, clauses, sentences, paragraphs, essays and documentation of information. Pertaining to the second semester, students are taken through topics such as: reports, letters, Curriculum Vitae writing, narration, exposition, argumentation, description and summary writing.

With respect to the organisation of the Communication Skills course in Ghanaian universities, three common practices exist: (1) the students are taught on programme basis. That is, lecturers are assigned to particular programmes, so instruction is given to the students together. For example, a Civil Engineering class will receive same tuition from one or more than one lecturer, but the nature of the content is derived from the same curriculum which is usually generalised for all students of a particular university, (2) in universities with relatively smaller number of candidates, especially on their distance programmes, all the first years are put together to take lessons in Communication Skills and (3) a hybrid class is derived where students freely select open groups with maximum cut off numbers. That is, groups with, say, a maximum number of 6o students are created and students pick which groups they want to belong, but groups are immediately closed once the maximum number is met. This results in a hybrid class since such Communication Skills classes are made up of students from different programme backgrounds. However, they receive the same tuition from one or more than one lecturer, but the nature of the content is derived from the same curriculum which is usually generalised for all students of a particular university.

At the university level, students are expected to demonstrate high levels of competence in communication in language skills such as Speaking, Writing, Listening and Reading - standards most of them are alien to. As Coker and Abude (2012) affirm, "university students are required to demonstrate express knowledge of writing in specific genres for specific communication endeavours, a task they have hardly been exposed to at the pre-tertiary level" (p. 2). It is, therefore, not surprising that Yankson (1994), Edu-Buandoh (1997), Dako, Dankabe and Forson (1997), Adika (1999), Agor (2010) and Mireku-Gyimah (2014) report that university students exhibit weaknesses such as errors with spelling, word choice, concord, tense, pronouns, ambiguity, punctuations and subordination. The Communication Skills course, therefore, aims to bridge the existing gap to enable students to fit better within the academic discourse community.

\subsection{The use of English language component of the MSEE for placement purposes and its effects on students}

As Boud (1995) espouses, examination is one of the core activities of educational institutions, the world over. It is at the heart of every educational institution, and it is of wide interest and concern to educators. An entrance examination is one type of examination that is frequently used in Ghana to admit candidates into universities, and one specific popular channel through which candidates gain access to universities in Ghana is the MSEE. Candidates are deemed qualified to partake in this examination on condition that they are not less than twenty-five years of age. Candidates must, in addition, have prior working experience (recognition of prior learning) in the fields that they seek to study. The common practice is that candidates are examined in three areas - English language, Mathematics and a subject specific paper. Candidates are expected to pass all the papers before they are deemed qualified for placement.

These examinations are mainly conducted internally by the universities in order to select the successful candidates for enrolment. For the English language component of the MSEE, which is the focus of this paper, the standards with respect to the competence areas and the language competences tested are not uniform since the universities manually set different questions to suit their internal purposes. In a study of the MSEE of six Ghanaian universities, Asafo-Adjei (2021) found that out of the four basic language skills (Speaking, Listening, Reading and Writing), only Reading and Writing were tested. In addition, the emerging competence areas generally tested are: Word Classes, Spelling, Registers, Literary Devices, Idioms and Idiomatic Expressions, Usage, Antonymy, Clausal Elements, Sentence Fragments and Misplaced Modifiers. Others are: Run-On Sentences, 
Dangling Modifiers, Punctuations, Synonymy, Summary, Essay Writing, Reading Comprehension and Subject-Verb Agreement.

Presently, the English language component of the MSEE is used for only placement purposes, so students with different strengths and weaknesses are placed together and given same tutelage on the Communication Skills course. The effects are that students with specific weaknesses do not get the necessary academic support to enable them cope with the demands of academic language skills. In addition, when the students with different strengths and weaknesses are put in the same class, some lose interest because some topics may not be relevant to them, probably because their levels may be higher or lower than what averagely pertains in the class. The effect of this is that most of the students who need academic support suffer and, consequently, perform poorly because of the absence of the necessary interventions to help them overcome the language skills in which they are weak. The present situation is worrying because studies have found, among other things, that essays, for instance, of first year university students in Ghana generally exhibit lapses such as: lack of cohesion and weak thematic progression which lead to flat paragraphs and undeveloped rhemes (Dako, 1997; Appiah, 2002; Adika, 2003), and such traces have a negative effect on students' general performances within the academic discourse community.

More so, it is noteworthy that university placement examination results are not very predictors of students' future performances in universities (Geiser \& Santelices, 2007). This position is corroborated by literature among which are quantitative studies which highlight the inherent weaknesses of entrance examinations used for placement purposes alone that such entrance examinations are not reliable predictors of how students will perform on the mainstream university programmes (Hughes \& Scott-Clayton, 2010; Belfield \& Crosta, 2012; Scott-Clayton, 2012). Arguing on a similar line, Grubb et al. (2011a) aver that one of the key objections of faculty about entrance examinations is that these examinations fail to offer diagnostic information to position instructors to understand students' strengths and weaknesses.

These inherent weaknesses of the university entrance examinations make it crucial that a dual approach be adopted in the conduct of the English language component of the MSEE so that the weakness can be offset to an extent by the adoption of the diagnostic/intervention approach. This is necessary because the English language component of the MSEE is crucial in the sense that most of the candidates who sit for this examination are normally professionals/workers who have been out of school for some time, so their language skills have grown a little rusty. Therefore, the right approaches have to be applied to aid instructors and curriculum designers to better understand the strengths and weaknesses of the candidates so that the appropriate interventions in the form of curriculum, text books and pedagogical approaches can be instituted to aid students perform better in the academic discourse community.

\section{Alternate Solutions and Ways Forward}

Apart from the placement purposes, it is proposed that the diagnostic/intervention component should be introduced for the English language component of the MSEE. The diagnostic/intervention component will involve using the English language component of the MSEE to test test takers' performances as a predictor of their performances in the mainstream Communication Skills course so that appropriate innovations are introduced to address candidates' identified weaknesses. As Jang and Wagner (n.d.) aver, 'the role of diagnostic feedback is not simply to provide learners with error corrections, but rather to address a cognitive gap between a current level of performance and some desired level of performance or goal' (p. 9).

In order to apply the diagnostic component to the examination, four overarching strategies are proposed: (1) the MSEE positioning, (2) the language assessors' role, (3) the mainstream Communication Skills positioning and (4) the policy makers' role. It is noteworthy that some of the strategies and responsible groups overlap, and because the universities are not homogenous with respect to facilities, human resource capacities and financial strengths, a number of strategies are 
suggested with the anticipation that some or particular ones will would fit for the universities to achieve the dual goal of using the English language component of the MSEE for both placement and diagnostic purposes.

Regarding the MSEE positioning, automated/e-based examinations software which can guarantee detailed placement and diagnostic feedback can be introduced in the conduct of the English language component of the MSEE. An automated test such as DIALANG which is a fast computer-based diagnostic test of language ability built to assess candidates' proficiency across reading, writing, listening, vocabulary and grammar structures (Alderson, 2000; Alderson, 2005; Alderson \& Huhta, 2005) can be used by the universities. Also, Criterion which is an electronically based web-based writing examination system which can give feedback on structural features such grammar, mechanics and style (Quinlan, Higgins \& Wolff, 2009; Jang \& Wagner, n.d.) can be given a serious look in order to have adaptable versions which will fit the Ghanaian setting. A growing body of research exist on the use of these automated tests for both placement and diagnostic purposes (Alderson, 2000; Alderson, 2005; Alderson \& Huhta, 2005; James, 2006; Shermis, Burstein, Higgins \& Zechner, 2010; Ramineni, 2013). An adoption of e-based examination software by Ghanaian universities would provide a faster and reliable placement and diagnostic feedback system as opposed to the fully manual approach to the administration and assessment of the English language component of the MSEE which often causes delays in feedbacks.

For the language assessors' core role, a detailed feedback on the MSEE revealing strengths and weaknesses of candidates so that test takers understand the nuances and the implications of their performances in the MSEE should be made readily available to the candidates and policy makers. The feedback that the two mentioned stakeholders receive can be used to place candidates into different language remediation groups based on the specific language weaknesses exhibited so that the teaching and learning process for the Communication Skills course can be meaningful and more focused for both the teachers and the learners. Because the different universities operating in Ghana have different Communication Skills curricula, such language groupings should be done at the individual university level. In addition, language assessors can be positioned to lend psychological/counselling support to those candidates with identified language weaknesses so that the candidates can embrace the weaknesses positively and work towards ameliorating such language weaknesses instead of seeing themselves as not up to the task.

Pertaining to the mainstream Communication Skills course positioning, an auxiliary bridging curriculum can be developed by language curriculum development experts to cater for key weaknesses identified for particular candidates. A bridging programme can then be organised for the candidates before the mainstream universities' academic years commence so that the candidates would be positioned well enough to cope with the tasks involved in the Communication Skills. This strategy will apply best to those universities with large student numbers and limited facilities such that applying extra remediation hours for candidates with special language deficiencies will be problematic.

With respect to the policy makers' role, the university managers can facilitate the planning of academic calendars to allow for time for remediation before the commencement of new academic years. They can equally engender: (1) the designing of curriculum to help remediation, (2) allowing for university timetable to be flexible enough to allow for extra contact hours for those in need of remediation and (3) the setting up of the language support centres. At such language support centres, especially trained instructors must be readily present to give extra specific language remediation support to candidates who may need such, based on the candidates' personal decisions or referral made by language assessors based on the diagnostic feedback of the English language component of the MSEE. Furthermore, policy makers can support language curriculum developers to design various intervention pedagogical approaches that teachers should use to address various weaknesses so that instructional material will be readily available for teachers to consult immediately particular learners are known to exhibit particular language weaknesses. Such instructional material can be developed based on piloting the MSEE for diagnostic purposes and using such results to inform the design of the Communication Skills syllabus and its associated instructional materials. 


\section{Conclusion}

It cannot be denied that the use of the English language component of the MSEE for placement purposes is very crucial as the examination serves as one of the key windows through which students gain admission into Ghanaian universities for undergraduate Studies. This notwithstanding, the placement purpose alone is inadequate since it is not an end in itself but a means to an end. Therefore, complementing it with the diagnostic/intervention purpose will position the examination strategically to: (1) select those that the examination predicts to have the language skills adequate for academic work and (2) identify and select those who need extra academic support so that appropriate interventions can be given them. When the proposed dual role (placement and diagnostic/intervention) is implemented, the full potential of the English language component of the MSEE would be realised.

\section{References}

Adika, G. S. K. (2003) A theme-structure approach to evaluating aspects of university students' expository texts, In E. K. Osam and G. S. K. Adika (eds.). Legon Journal of the Humanities, 14, 55-78.

Afful, J. B. A. (2007). Academic literacy and Communicative Skills in the Ghanaian university: A proposal. Nebula, $4(3), 141-159$.

Alderson, J. C. (2000). Assessing reading. The Cambridge Language Assessment Series. Cambridge: Cambridge University Press.

Alderson, J. C. (2005). Diagnosing Foreign Language Proficiency: The Interface Between Learning and Assessment. London: Continuum.

Alderson, J. C., \& Huhta, A. (2005). The development of a suite of computer-based diagnostic tests based on the Common European Framework. Language Testing, 22, 301-320.

Asafo-Adjei, R. (2021). An Evaluation of the English Language Component of The Mature Students' Entrance Examinations into Selected Ghanaian Universities. Unpublished PhD. Thesis: University of Venda.

Baldauf, R. B., \& Dawson, R. L. T. (1980). The predictive validity of the Michigan test of English Language proficiency for teacher trainees in Papua New Guinea. Educational and Psychological Measurement, 12011205 .

Belfield, C., \& Crosta, P. (2012). Predicting Success in College: The Importance of Placement Tests and High School Transcripts, Working Paper No. 42. New York, NY: Community College Research Center, Teachers College, Columbia University.

Berry, V. (2018). Characteristics of quality assessment, The TESOL Encyclopedia of English Language Teaching (1 ${ }^{\text {st }}$ ed.), Edited by JI Liontas. John Wiley \& Sons, Inc.

Boud, D. (1995). Assessment and higher learning: Contradictory or complementary? Assessment for Learning in Higher Education, (pp. 35-48), London: Kogan Page.

Briggs, D. C., Alonzo, A. C., Schwab, C., \& Wilson, M. (2006). Diagnostic assessment with ordered multiple-choice items. Educational Assessment, 11(1), 33-63.

Brown, H. D. (2004). Language Assessment: Principles and Classroom Practices. London: Longman.

Carroll, B. J. (1980). Testing Communication Performance. Oxford: Pergamon.

Coker, W., \& Abude, F. M. (2012). Referral trends among students of the Communicative Skills course in a Ghanaian university. English for Specific Purposes World, 12(36).

Dako, K., Dankabe, A., \& Forson, E. B. (1997). The Ghanaian university students' knowledge of grammar. In M. E. Kropp Dakubu (Ed.). English in Ghana (53-68). Accra: Ghana Universities Press.

De Pierola, S. (2014) What is Diagnostic Assessment? https://prezi.com/m/ektdwrvwczn7/what-is-diagnosticassessment/ Accessed 16 May 2020.

Edu-Buandoh, D. F. (1997). A preliminary report on the study of error patterns in the written essays of senior secondary students. In M. E. Kropp Dakubu (Ed.), English in Ghana (pp. 195-210). Accra: Ghana Universities Press.

EL-Hamid, S. H. A. (2011). nurfac.mans.edu.eg Accessed 14 February 2019.

Fletcher, D (2009) Brief history: Standardised testing, Time Magazine, Friday, Dec. 11. Retrieved from: http://content.time.com/time/nation/article/o,8599,1947019,oo.html Accessed 13/o2/18

Geiser, S., \& Santelices, M. V. (2007). Validity of High-School Grades in Predicting Student Success beyond the Freshman Year: High-School Record vs. Standardized Tests as Indicators of Four-year College Outcomes. Berkeley, CA: Center for Studies in Higher Education, University of California, Berkeley. 
Grubb, W. Norton, et al. (2011a). Assessment and alignment: The dynamic aspects of developmental education. Working Paper. Stanford, CA: Policy Analysis for California Education.

Hanna, G. S., \& Dettner, P. A. (2004). Assessment for Effective Teaching: Using Context-Adaptive Planning. Boston, MA: Pearson A\&B.

Harding, L., Alderson, J. C., \& Brunfaut, T. (2015). Diagnostic assessment of reading and listening in a second or foreign language: Elaborating on diagnostic principles. Language Testing, 3(3), 317-336.

Hughes, K. L., \& Scott-Clayton, J. (2010). Assessing developmental assessment in community colleges: A review of the literature. Working Paper No. 19. New York, NY: Community College Research Center, Teachers College, Columbia University.

James, C. L. (2006). Validating a computerised scoring system for assessing writing and placing students in composition courses. Assessing Writing, 11(3), 167-178.

Jang, E. E., \& Wagner, M. (2013). Diagnostic feedback in language classroom. In A. Kunnan (Ed.). Companion to Language Assessment. Wiley-Blackwell.

Jang, E. E., \& Wagner, M. (n.d.). Diagnostic feedback in language classroom. In A. Kunnan (Ed.), Companion to Language Assessment. Wiley-Blackwell.

Kim, Y. H. (2011). Diagnosing EAP writing ability using the Reduced Parameterized Unified Model. Language Testing, 28(4), 509-541.

Kodom-Gyasi, W., Nartey, T. A., \& Coker, W. (2011). A preliminary report on first Year university students' basic knowledge of grammar. Current Journal of Social Sciences, 3(5), 399-405.

Lee, Y. (2015). Diagnostic language assessment. Language Testing, 32(3), 299-316.

Mireku-Gyimah, P. B. (2014). Analysis of errors in the English of final year university students: A case study at the University of Mines and Technology. Journal of ELT and Applied Linguistics (JELTAL), 2(4), $23-46$.

Quinlan, T., Higgins, D., \& Wolff, S. (2009). Evaluating the Construct Coverage of the e-rater Scoring Engine. Princeton, NJ: Educational Testing Service.

Ramineni, C. (2013). Validating automated essay scoring for online writing Placement. Assessing Writing, 18(1), 4061.

Reed, D. (2006). Diagnostic assessment in language teaching and learning. Clear News, 2(2), 1-7.

Sandra, K., \& Scaife, J. (2012). Misunderstood and neglected? Diagnostic and formative assessment practices of lecturers. Journal of Education for Teaching, 38(2), 181-192.

Scott-Clayton, J. (2012). Do High-Stakes Placement Exams Predict College Success? New York: Community College Research Center.

Shermis, M. D., Burstein, J., Higgins, D., \& Zechner, K. (2010). Automated Essay Scoring: Writing Assessment and instruction. In P. Peterson, E. Baker, \& B. McGraw (Eds.). International Encyclopedia of Education ( ${ }^{\text {rd }}$ ed.) (pp. 20-26). Oxford, UK: Elsevier.

Sternberg, R. J., \& Grigorenko, E. L. (2002). Dynamic Testing: The Nature and Measurement of Learning Potential. Cambridge: Cambridge University Press.

Tozcu, A. (2015). The effectiveness of diagnostic assessment on the development of Turkish Language learners' narrative skills as an oral proficiency interview (OPI). Journal of the National Council of Less Commonly Taught Languages, 19, 61-96.

UNESCO (2005). Diagnostic Teaching for Primary Level Schooling. Accra: UNESCO.

Wornyo, A. A., \& Klu, E. K. (2018). The contribution of intercultural rhetoric research to the teaching of academic writing skills. The Social Sciences, $13(2)$, 391-398.

Xiaojiang, H. (1991). Term examinations, general graduation examinations, and college entrance examinations. Educational Research in Leshan, 1, 46-48.

Yankson, K. E. (1994). Better English through Concord for West African Students. Uruowulu Obosi: Pacific College Press.

Zwick, R. (2002). Fair game? The Use of Standardised Admissions Tests in Higher Education. New York: Routledge Falmer 